\title{
Bioresource collections of vegetable plants as an initial material for breeding cultivars with high biochemical value and for obtaining functional foods
}

\author{
Fotev Y.V.* \\ Central Siberian Botanical Garden, SB RAS, Novosibirsk, Russia \\ *e-mail:fotev_2009@mail.ru
}

The human habitat that has deteriorated in recent decades causes drastic changes in the assortment and variety of foodstuffs. It greatly contributes to the reduction of their biological value. Bioresource collections of vegetable plants created in Russia successfully used for breeding cultivars of cultivated plants and introduction of new crops. The breeding of vegetable crops - super producers of biologically active substances distinguished by the stability of this trait is an important task for the near future. The Central Siberian Botanical Garden SB RAS (CSBG) create a genebank of vegetable seeds and related wild species, numbering 10754 samples, including 133 species belonging to 44 genera and 13 families. Based on the registered collection UNU No. USU 440534 for the first time in Russia 5 varieties of new cultures have created and included in the Russian State Register of Breeding Achievements: cultivars of cowpea (Vigna unguiculata), bitter melon (Momordica charantia), kiwano (Cucumis metuliferus) and wax gourd (Benincasa hispida) distinguished by their high biochemical value. The content of ascorbic acid in the fruits of cowpea samples reaches $83.9 \mathrm{mg} \%$ (cultivar Yunnanskaya), whereas in common bean not exceed $22.9 \mathrm{mg} \%$. Bitter melon fruits are distinguished by their high content of carotenoids (68.9-177.6 mg\% in aryllus), $350.8-545.1 \mathrm{mg} \%$ in leaves, FW and ascorbic acid (72.5-127.5 mg\%). Elevated concentrations of $\mathrm{Zn}$ are noted in the fruits of bitter melon, cowpea and kiwano $(32.9-57.6 \mu \mathrm{g} / \mathrm{g})$ whereas its content in the fruits of tomato is $18.5 \mu \mathrm{g} / \mathrm{g}$. The fruits of cowpea accumulate an increased amount of Mo $(5.47 \mu \mathrm{g} / \mathrm{g})$. Coefficient of variation $(\mathrm{Cv})$ of the macro-element content $(\mathrm{K}, \mathrm{Na}, \mathrm{Ca}, \mathrm{Mg}, \mathrm{Fe})$ in the cowpea seeds, when grown in 2018 in the CSBG and in the Nikitsky Botanical Garden, Crimea was the smallest in cv. "Siberskiy razmer" and sample of Vigna catjang (14.3\%). 